\title{
Dynamic behavior of pile-supported wharves by slope failure during earthquake via centrifuge tests
}

\author{
Jung-Won Yun ${ }^{1}$ and Jin-Tae Han²*
}

\author{
${ }^{*}$ Correspondence: \\ jimmyhan@kict.re.kr \\ ${ }^{2}$ Department \\ of Infrastructure Safety \\ Research, Korea Institute \\ of Civil Engineering \\ and Building Technology, \\ Goyang, Gyeonggi, South \\ Korea \\ Full list of author information \\ is available at the end of the \\ article
}

\begin{abstract}
The effects of earthquakes on pile-supported wharves include damage to piles by inertial forces acting on the superstructure, and damage caused by horizontal displacement of retaining walls. Piles can also be damaged through kinematic forces generated by slope failure. Such forces are significant but it is difficult to clearly explain pile damage during slope failure since the inertial force of superstructure and the kinematic force by slope failure can occur simultaneously during an earthquake. In this study, dynamic centrifuge model tests were performed to evaluate the effect of the kinematic force of the ground due to slope failure during earthquake on the behavior of a pile-supported wharf structure. Experimental results indicate that the slope failure in the inclined-ground model caused the deck plate acceleration and pile moment to be up to $24 \%$ and $31 \%$ respectively greater than those in the horizontal-ground model due to the kinematic force of the ground.
\end{abstract}

Keywords: Pile-supported wharf, Dynamic centrifuge test, Inclined ground, Slope failure

\section{Introduction}

Pile-supported structures are important in port infrastructure. They essentially comprise piles supporting a deck and the embankment, and can be classified as wharves, piers, or jetties depending on the type of structure. Pile-supported wharves lie parallel to the coast with little width in the offshore direction, and are constructed on inclined embankments sloping down towards the sea (Fig. 1). Conversely, pile-supported piers and jetties are constructed perpendicular to the shore and can be particularly long, projecting $0.5-5.0 \mathrm{~km}$ out to sea. These structures encounter flatter embankments than wharves, mainly along the sea floor $[1,2,12]$.

Generally, pile foundation such as pile-supported structures, can be affected by force components during an earthquake shown in Fig. 2. The pile foundations can be affected by inertial forces acting on superstructure and piles, by subgrade reaction force by $\mathrm{p}-\mathrm{y}$ spring or coefficient of subgrade reaction, and through kinematic forces generated by ground movement [17]. In particular, it has been reported that the effect of the kinematic forces of the ground due to slope failure can cause severe

c) The Author(s), 2021. Open Access This article is licensed under a Creative Commons Attribution 4.0 International License, which permits use, sharing, adaptation, distribution and reproduction in any medium or format, as long as you give appropriate credit to the original author(s) and the source, provide a link to the Creative Commons licence, and indicate if changes were made. The images or other third party material in this article are included in the article's Creative Commons licence, unless indicated otherwise in a credit line to the material. If material is not included in the article's Creative Commons licence and your intended use is not permitted by statutory regulation or exceeds the permitted use, you will need to obtain permission directly from the copyright holder. To view a copy of this licence, visit http:// creativecommons.org/licenses/by/4.0/. 


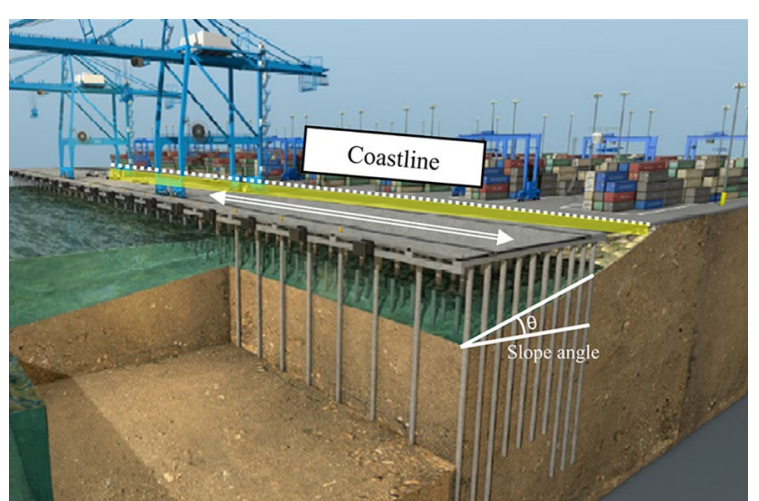

Fig. 1 Pile supported wharf structure [12]

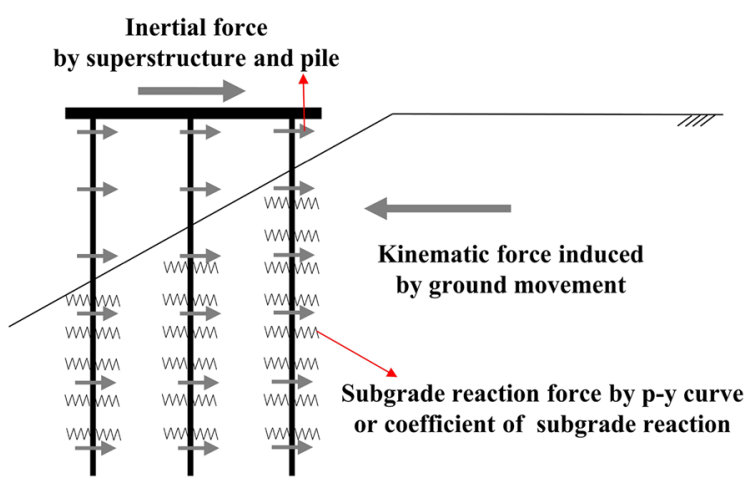

Fig. 2 Force components of pile foundation during earthquake [17]

damage on to the structure. The M 7.8 earthquake in the Philippines in 1990 significantly damaged pile-supported structures at San Fernando Port. Slope failure caused piles to displace horizontally by $1.5 \mathrm{~m}$; the deck suffered many cracks, and the pile cap collapsed [11]. The M 7.2 Kobe earthquake in 1995 caused extensive damage to Takahama Wharf at Kobe Port. Horizontal displacements of 1.3-1.7 m occurred in the alluvial sand layer under the rubble mound, and piles tilted about $3^{\circ}-4^{\circ}[9]$. The M 7.2 magnitude earthquake striking Israel in 1995 caused slope failure at the main wharf of the port of Eilat, with expansion-joint displacement of 5-15 mm [11].

Kinematic forces on inclined ground can significantly damage piles. Several experimental and analytical works have studied pile-supported structures installed on inclined ground: for example, McCullough [6] performed a number of dynamic centrifuge model tests and numerical analyses to study ground and pile deformation due to ground liquefaction. Pile moment, deck-plate acceleration and displacement, and ground pore-water pressure were measured throughout the experiments and compared with analytical results. Takahashi and Takemura [15] performed dynamic centrifuge model tests and analyses of Takahama Wharf in Kobe, Japan, and effectively simulated the moment behavior of piles due to horizontal displacement of the ground. Their results indicate that horizontal displacement of the ground occurred 
due to liquefaction and that the pile moment greatly increased. Su et al. [14] evaluated the performance of a pile-supported wharf through 3D numerical analysis. The pile moment, shear force, and axial force caused by deformation of the ground were comprehensively evaluated through numerical analysis.

As indicated above, due to the kinematic force by slope failure, significant damage can occur to the pile structure, and a number of studies have been conducted to simulate it. However, since the inertial force of superstructure and the kinematic force by slope failure can occur simultaneously during an earthquake, it is difficult to examine only the effects of the kinematic force. In this study, dynamic centrifuge model tests of pilesupported structure constructed on horizontal and inclined ground were performed to investigate the effects of kinematic force during slope failure on the behavior of the structure.

\section{Dynamic centrifuge model tests}

Dynamic centrifuge model test simulates the confining pressure of the ground by applying centrifugal force to a reduced-size model. The experiments in this study were conducted at the KAIST Geo-Centrifuge Center with a $5 \mathrm{~m}$ radius centrifuge machine (Daejeon, Korea) [3]. The tests used a square equivalent shear beam (ESB) model box. The inner dimensions of ESB box is $49 \mathrm{~cm}, 49 \mathrm{~cm}$, and $63 \mathrm{~cm}$ in width, length, and height, respectively [4]. The inclined-ground model in Fig. 3b was that reported by Yun et al. [18].

The experiment considered a $3 \times 3$ pile groups of the pile-supported structure in Pohang, South Korea. Figure 3 shows the two configurations of horizontal (HA45) and inclined (IA40) ground in the prototypes. The ground was simplified as a single layer of sandy soil; different relative densities of soil were used in four models: HA 45 had soil of $45 \%$ relative density in a horizontal-ground configuration; IA40 had inclined ground $\left(33^{\circ}\right)$ with the soil relative density adjusted to $40 \%$. In case of the seismic test in which a horizontal load is applied, the large bending moment of the piles can occur. Therefore, model piles were manufactured by considering the bending

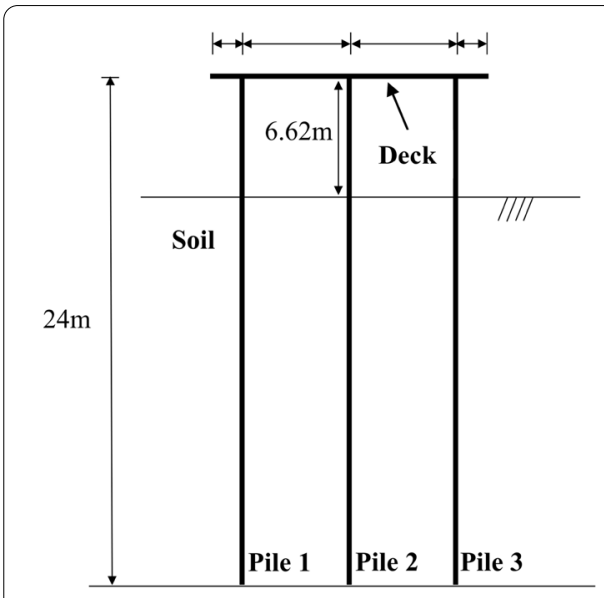

(a)



(b)

Fig. 3 Dynamic centrifuge prototypes: a HA45, b |A40 
stiffness of the prototype and model piles. A deck plate was manufactured by considering the mass of the prototype and model deck. Each model was made at a 1/48 scale ratio, and the scale factors and values for the tests are shown in Table 1 [7, 13, 16]. The model piles and plate were manufactured by aluminum (Aluminum; Elastic modulus $=68,300 \mathrm{Mpa}$; Poisson ratio, $v=0.3$ ); Table 2 gives details.

For the ground composition, the silica sand with an average particle diameter $\left(D_{50}\right)$ of $0.3 \mathrm{~mm}$ were used; Table 3 lists its basic properties. The model pile was fixed to the base for simulating the end-bearing pile, and the relative density of the soil was adjusted by air pluviation. The slope was adjusted using a vacuum machine. All

Table 1 Model scaling factors and values

\begin{tabular}{lll}
\hline & Centrifuge scale factors & Prototype/model \\
\hline Acceleration $(\mathrm{g})$ & $\mathrm{n}^{-1}$ & 0.021 \\
Velocity $(\mathrm{m} / \mathrm{s})$ & 1 & 1 \\
Length $(\mathrm{m})$ & $\mathrm{n}$ & 48 \\
Time $($ Dynamic) $(\mathrm{s})$ & $\mathrm{n}$ & 48 \\
Mass density $\left(\mathrm{kN} / \mathrm{m}^{3}\right)$ & 1 & 1 \\
Mass $(\mathrm{kg})$ & $\mathrm{n}^{3}$ & 110,592 \\
Force $(\mathrm{kN})$ & $\mathrm{n}^{2}$ & 2,304 \\
Stress $\left(\mathrm{kN} / \mathrm{m}^{2}\right)$ & 1 & 1 \\
Pile Stiffness $(E l)\left(\mathrm{kN} \mathrm{m}^{2}\right)$ & $\mathrm{n}^{4}$ & $5,308,416$ \\
Moment $(\mathrm{kN} \mathrm{m})$ & $\mathrm{n}^{3}$ & 110,592
\end{tabular}

I moment of inertia of each pile, $E$ pile elastic modulus, $n$ scaling factor: $\mathrm{n}=$ prototype/model for a centrifuge acceleration of $48 \mathrm{~g}$

Table 2 Prototype and model properties

\begin{tabular}{llc}
\hline & Prototype & Model \\
\hline Pile & & \\
Diameter $(\mathrm{mm})$ & 914 & 19 \\
Thickness $(\mathrm{mm})$ & 14 & 1 \\
Length $(\mathrm{mm})$ & 24,000 & 500 \\
Density $\left(\mathrm{kN} / \mathrm{m}^{3}\right)$ & 78.5 & 26.4 \\
Flexural rigidity $\left(\mathrm{kNm}^{2}\right)$ & $7.81 \times 10^{5}$ & 0.147 \\
Deck & & 20 \\
Thickness $(\mathrm{mm})$ & 1000 & 26.4 \\
Density $\left(\mathrm{kN} / \mathrm{m}^{3}\right)$ & 24.5 & \\
\hline
\end{tabular}

Table 3 Properties of silica sand

\begin{tabular}{ll}
\hline Soil type & Silica sand \\
\hline USCS & $S P$ \\
$C_{c}$ & 1.16 \\
$C_{u}$ & 1.96 \\
$G_{S}$ & 2.63 \\
$\gamma_{d \cdot \max }\left(k N / m^{3}\right)$ & 16.5 \\
$\gamma_{\text {d.min }}\left(k N / m^{3}\right)$ & 12.4 \\
\hline
\end{tabular}


experiments used single dry sandy soil in order to consider only the kinematic force of slope on the structure without the effect of the excess pore pressure.

The input wave was an artificial earthquake of a type specified by the Korean Ministry of Ocean and Fisheries [8], as shown in Fig. 4a. The design ground acceleration reflects the characteristics of the Korean site, and is expressed as response spectrum curves with a $5 \%$ damping ratio. Figure $4 \mathrm{~b}$ shows that the response spectrum curve of an artificial wave with the standard design response spectrum curve. Experiments were carried out with the peak acceleration of each model increasing from 0.04 to $0.23 \mathrm{~g}$. In KAIST Geocentrifuge Center, it is difficult to accurately simulate the planned input acceleration due to the system limitations. Therefore, the experiment was performed by gradually increasing the input acceleration to the stage.

Figure 5 gives details of the model section and the instrumentation locations. 5 laser displacement meters, 14 accelerometers, and 42 strain gauges were used. The laser displacement meters could measure residual displacement, but had limit the sample rate, which makes it difficult to accurately measure displacement over time.

\section{Dynamic centrifuge model test results}

\section{Comparison of the time-history response}

Figure 6 compares the acceleration and moment time-history responses of models HA45 and IA40. All experimental data were converted to responses of the prototype. The Fig. $6 \mathrm{a}$ shows the HA45 model (input ground acceleration: $0.23 \mathrm{~g}$ ) and Fig. $6 \mathrm{~b}$ shows the IA40 model $(0.23 \mathrm{~g})$.

Looking the results of the acceleration (A1, A2) of the two models in Fig. 6, it can be seen that the response in the ground surface (A2) increases significantly compared to the response in the bedrock (A1). This is because in both of horizontal and inclined ground models, ground amplification occurred in which the acceleration response increased on the ground surface. Also, comparing the results of the acceleration time history of deck plate (A3), the greater acceleration time history values derived in the inclined ground model than the horizontal ground model. Note that the top plate acceleration (A3) of model IA40 exhibited a much greater maximum acceleration when moving landward $(0.56 \mathrm{~g})$ than when moving seaward $(0.46 \mathrm{~g})$.

The Fig. 6 shows the moment time history of models HA45 (0.23 g) and IA40 (0.23 g). Depth profile of the pile moments in models HA45 and IA40 are shown in Fig. 7. The plots clearly show where the maximum moment occurred. The pile labeled 1,2 , and 3 , as in Fig. 5. The moment time history (S1-S3) show no significant differences for the piles

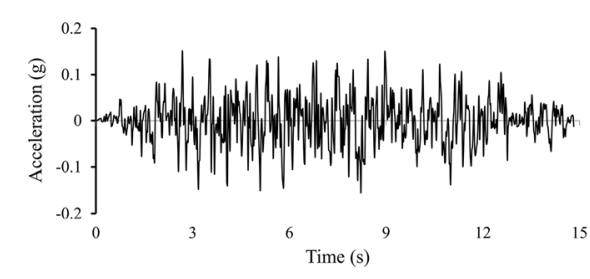

(a)

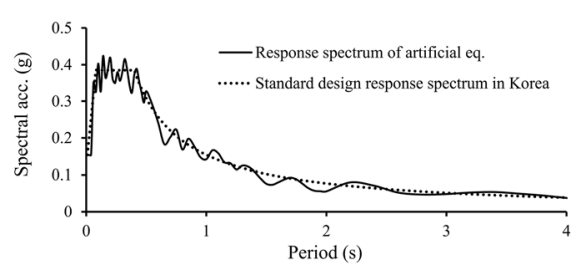

(b)

Fig. 4 a Input seismic wave and $\mathbf{b}$ comparison of the response spectra [18] 

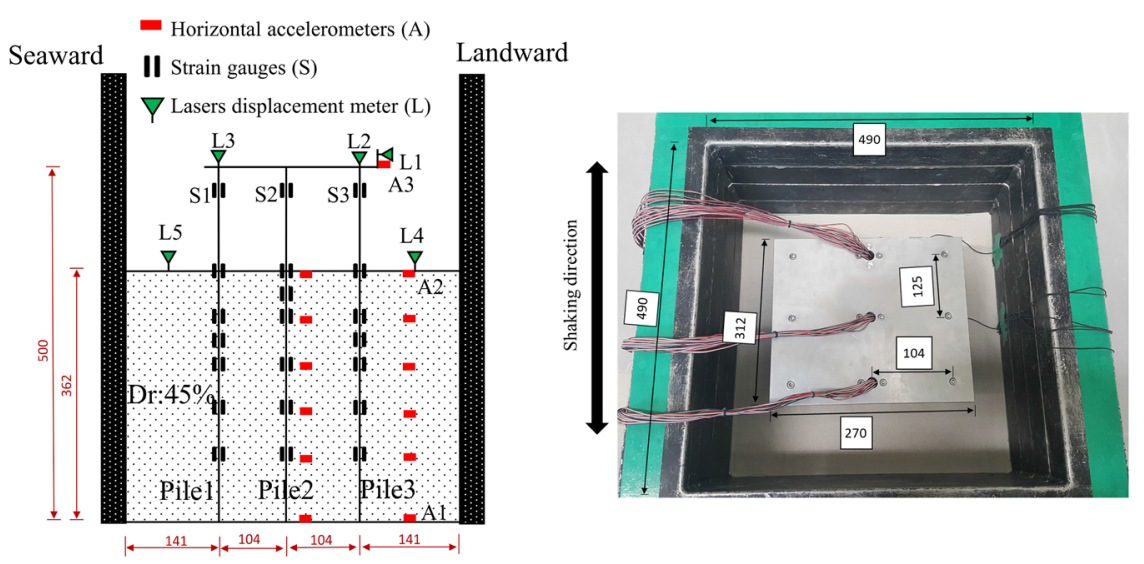

(a)
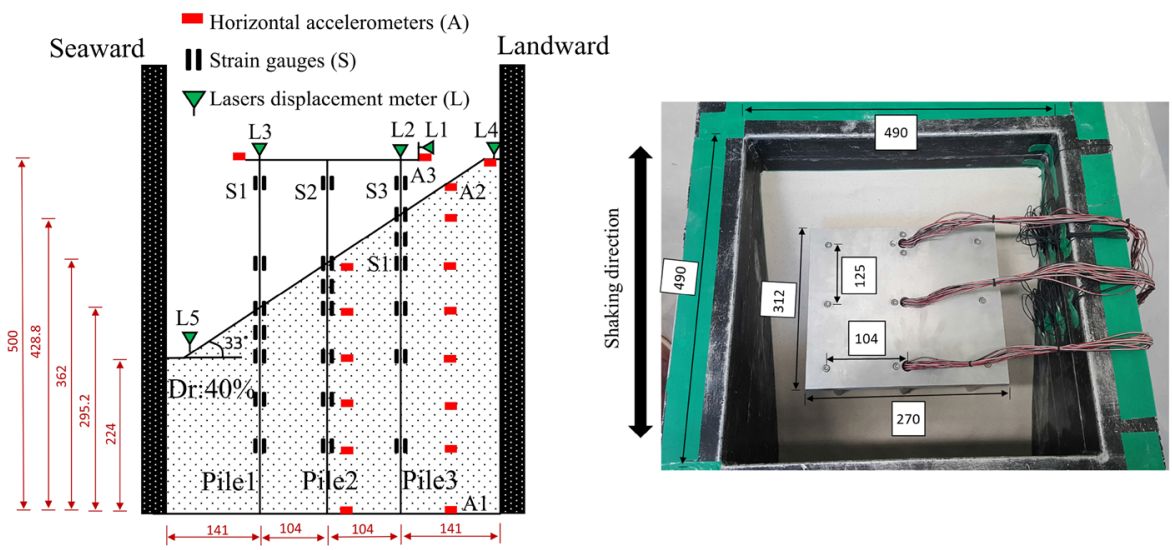

(b)

Fig. 5 Cross-section and experimental models a HA45, b IA40 (unit: mm)
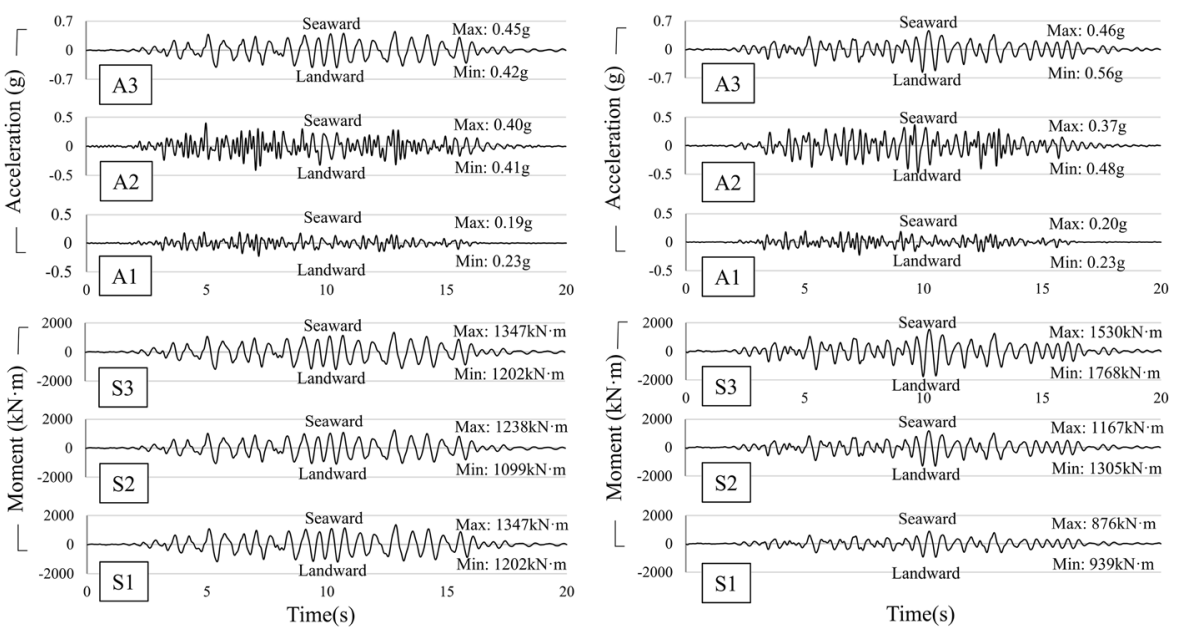

(a)

(b)

Fig. 6 Time history curves for models a HA45 (0.23 g) and b IA40 (0.23 g) 
Pile moment $(\mathrm{kN} \cdot \mathrm{m})$

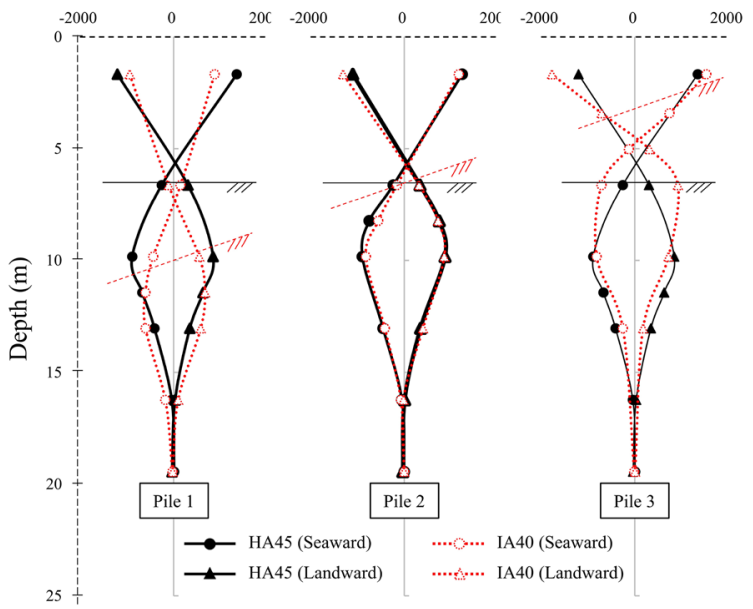

Fig. 7 Depth profiles of the pile moments of HA45 and IA40 model

in horizontal ground, whereas the maximum moment increased in order from S1 to S3 in the inclined ground model. This seems to be because pile 3 has the deepest ground length, so it is most likely to be affected by the kinematic force of ground due to horizontal displacement during earthquake. In particular, the moment of S3 showed a much larger response when moving landward $(1768 \mathrm{kN} \mathrm{m})$ than when moving seaward (1530 $\mathrm{kN} \mathrm{m}$ ). This is because the height of the ground on the landward is higher than on the seaward, so it appears that a greater lateral soil resistance occurs when pile moves to the landward. According to Nguyen et al. [10] who performed a centrifuge model test by applying a sine wave to the same model as this experiment, when the pile moves toward the landward, the lateral soil resistance can be generated up to four times greater than when pile moves toward the seaward. As the lateral soil resistance increases, the moment generated in the pile also appears to increase.

\section{Comparison of test results respect to the input acceleration}

Figure 8 compares displacements for models HA45 and IA40 in Fig. 5a, b. Their cumulative vertical ground displacement with respect to input acceleration is shown in Fig. 8a. HA45 showed subsidence of the horizontal ground (L4), and IA40 showed soil subsidence at the top of the slope (L4) and soil uplift at the bottom of the slope (L5) due to slope failure. Both models showed little soil subsidence at input accelerations of up to $0.12 \mathrm{~g}$; at higher accelerations, their displacements varied significantly. The horizontalground model showed little soil subsidence of $67 \mathrm{~mm}$ in total. On the other hand, the inclined-ground model showed simultaneous soil subsidence at the top of the slope (more than $200 \mathrm{~mm}$ ) and uplift at the bottom (rising by $140 \mathrm{~mm}$ ). The results confirm slope failure in IA40, with the subsidence being about $60 \mathrm{~mm}$ greater than the uplift. This was because subsidence occurred in the entire ground when slope failure occurred.

Figure $8 \mathrm{~b}$ shows the cumulative horizontal displacement of the deck plate in the two models with respect to the input acceleration. Similar to the vertical displacement, the models' horizontal displacements diverged significantly at an input acceleration of 


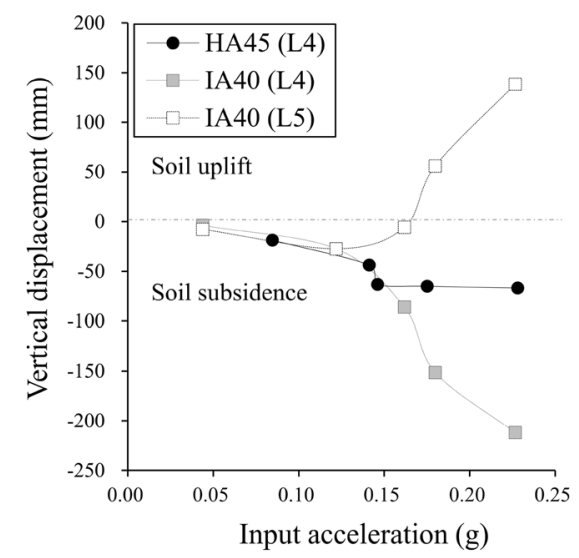

(a)

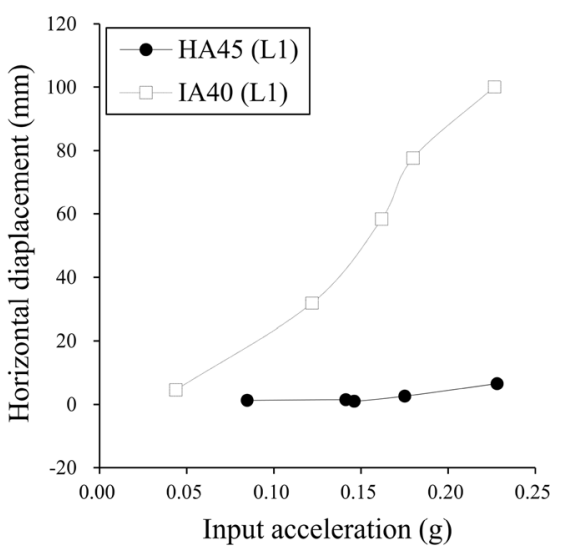

(b)

Fig. 8 Comparison of a vertical residual displacement of ground, b horizontal residual displacement of deck plate with respect to input acceleration (scaled to the prototype)

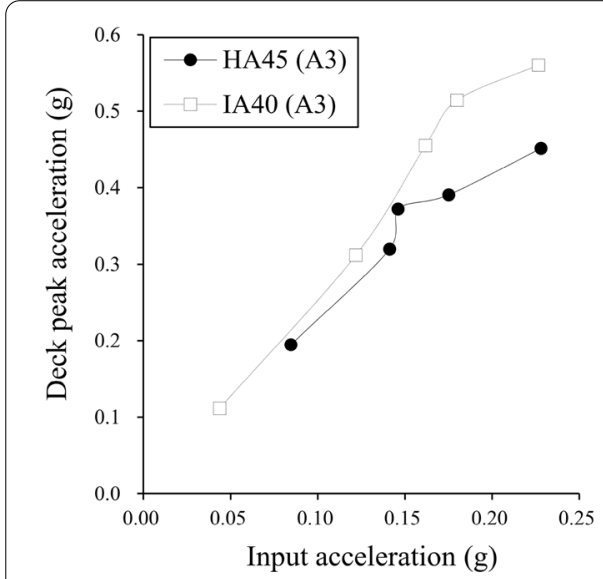

(a)

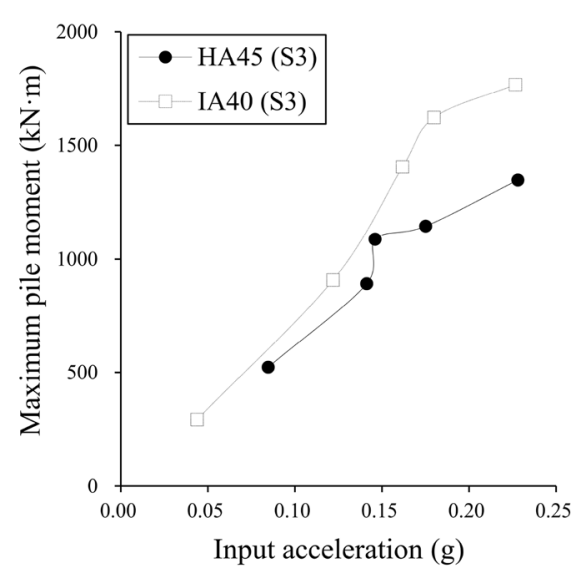

(b)

Fig. 9 Comparison of a peak acceleration of deck plate, $\mathbf{b}$ maximum pile moment with respect to input acceleration (scaled to the prototype)

$0.12 \mathrm{~g}$. In the horizontal-ground model, there was almost no residual displacement of the deck plate (totaling $7 \mathrm{~mm}$ ). The inclined-ground model, however, showed a total residual displacement of $100 \mathrm{~mm}$, about 15 times that of the horizontal ground.

Figure 9 shows the peak deck plate acceleration and the maximum pile moment with respect to the input acceleration of the two models. Figure 9a compares the peak horizontal acceleration of the deck plate, showing that the models behaved similarly up to an input acceleration of $0.12 \mathrm{~g}$, at which slope failure commenced and large acceleration differences occurred. At an input acceleration of $0.23 \mathrm{~g}$, the deck plate acceleration was $0.45 \mathrm{~g}$ in the horizontal-ground model and about $24 \%$ greater in the inclined-ground model $(0.56 \mathrm{~g})$. 
Figure 9b compares the models' maximum pile moments. As for the other data, the models' moments diverged greatly at an input acceleration of $0.12 \mathrm{~g}$, when slope failure began. At an input acceleration of $0.23 \mathrm{~g}$, the moments were $1347 \mathrm{kN} \mathrm{m}$ for the horizontal-ground model and $1768 \mathrm{kN}$ m for the inclined-ground model, about 31\% greater. These results show that the peak deck acceleration and maximum pile moment increased significantly at slope failure in the inclined-ground model. This was attributed to slope failure applying kinematic force to the ground, which resulted in an additional response in the structures.

Figure 10 compares the cumulative soil subsidence and uplift of the inclined-ground models of Fig. 8a. The magnitudes of soil subsidence and uplift in Fig. 10 are enlarged by a factor of five to emphasize the cumulative displacement. Subsidence in the middle of the slope was not measured here, although the shape of each slope after the experiment was derived from photographs. The figure shows that planar failure of the slope occurred at its top, and the ground height increased at its bottom. Planar failure involves a failure surface crossing the crest of the slope, and can occur in slopes with a soft layer [5]. The figure shows that planar failure only occurred at the slope's crest. The piles appear to have had a stabilizing effect, preventing failure in the middle of the slope.

\section{Conclusions}

In this study, dynamic centrifuge model tests of pile-supported structure installed on horizontal and inclined ground were performed to investigate the effects of kinematic force during slope failure on the behavior of the structure. The following conclusions were obtained.

The deck plate acceleration and pile moment results showed that additional kinematic force occurred on the inclined ground in the seaward direction during an earthquake. This resulted in a large ground reaction when the pile moved landward, with the kinematic force of the slope causing an additional response in the pile.

The vertical displacement results show that the inclined-ground model experienced great slope failure, while the horizontal-ground model did not. The structures in both models responded similarly prior to slope failure, but their responses differed significantly afterwards. Slope failure in the inclined-ground model caused the deck plate

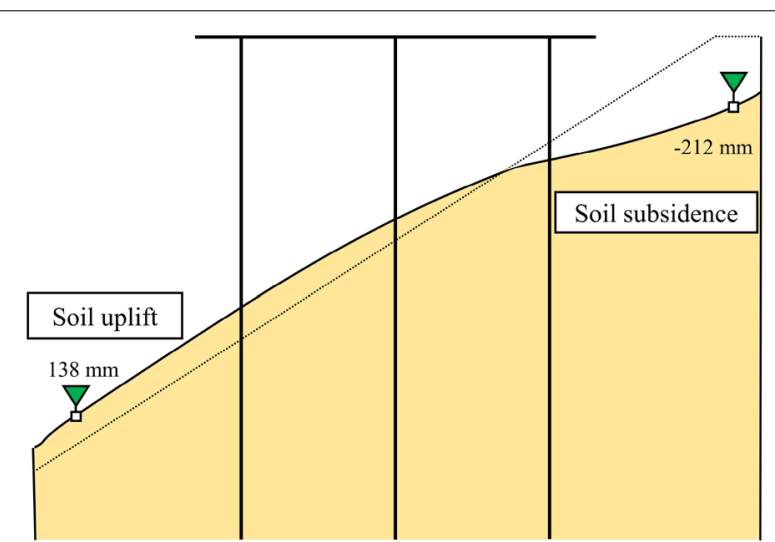

Fig. 10 Vertical residual displacement of inclined ground model (scales are enlarged by 5 times from the prototype) 
acceleration and pile moment to be up to $24 \%$ and $30 \%$ respectively greater than those in the horizontal-ground model due to the kinematic force of the ground.

When performing the equivalent static analysis and response spectrum analysis, a representative simple analysis method of pile-supported structure, the kinematic force of ground due to slope failure has not been properly considered. Since this study showed that the response of structure can be greatly changed due to slope failure, it is necessary to develop a modeling method that can properly simulate the kinematic forces of the ground is needed.

\section{Acknowledgements}

This research was supported by the project entitled "Development of performance-based seismic design technologies for advancement in design codes for port structures" funded by the Ministry of Oceans and Fisheries of Korea and by the project entitled "Construction technologies program (21SCIP-C151438-03)" funded by the Ministry of Land Infrastructure and Transport of Korea.

\section{Authors' contributions}

All authors read and approved the final manuscript.

Availability of data and materials

Not applicable.

\section{Code available}

Not applicable.

\section{Declarations}

\section{Completing interests}

The authors declare that they have no competing interests.

\section{Author details}

${ }^{1}$ Department of Civil Engineering, Korea Army Academy at Yeongcheon, Yeongcheon, South Korea. ${ }^{2}$ Department of Infrastructure Safety Research, Korea Institute of Civil Engineering and Building Technology, Goyang, Gyeonggi, South Korea.

Received: 21 April 2020 Accepted: 11 July 2021

Published online: 22 November 2021

\section{References}

1. Balomenos GP, Padgett JE (2017) Fragility analysis of pile-supported wharves and piers exposed to storm surge and waves. J Waterw Port Coast Ocean Eng 144(2):04017046. https://doi.org/10.1061/(ASCE)WW.1943-5460.0000436

2. Cuomo G, Tirindelli M, Allsop W (2007) Wave-in-deck loads on exposed jetties. Coast Eng 54(9):657-679. https://doi. org/10.1016/j.coastaleng.2007.01.010

3. Kim DS, Kim NR, Choo YW, Cho GC (2013) A newly developed state-of-the-art geotechnical centrifuge in Korea. KSCE J Civ Eng 17(1):77-84. https://doi.org/10.1007/s12205-013-1350-5

4. Lee SH, Choo YW, Kim DS (2013) Performance of an equivalent shear beam (ESB) model container for dynamic geotechnical centrifuge tests. Soil Dyn Earthq Eng 44:102-114. https://doi.org/10.1016/j.soildyn.2012.09.008

5. Ling HI, Mohri Y, Kawabata T (1999) Seismic analysis of sliding wedge: extended Francais-Culmann's analysis. Soil Dyn Earthq Eng 18(5):387-393. https://doi.org/10.1016/S0267-7261(99)00005-6

6. McCullough NJ (2004) The seismic geotechnical modeling, performance, and analysis of pile-supported wharves. Dissertation, University of Oregon

7. McCullough NJ, Dickenson SE, Schlechter SM, Boland JC (2007) Centrifuge seismic modeling of pile-supported wharves. Geotech Test J 30(5):349-359. https://doi.org/10.1520/GTJ14066

8. MOF (Ministry of Oceans and Fisheries) (2014) Design standards of harbour and port. Ministry of Oceans and Fisheries, Sejong (in Korean)

9. Nozu A, Ichii K, Sugano T (2004) Seismic design of port structures. J Jpn Assoc Earthq Eng 4(3):195-208. https://doi. org/10.5610/jaee.4.3_195

10. Nguyen BN, Tran NX, Han JT, Kim SR (2018) Evaluation of the dynamic p-yp loops of pile-supported structures on sloping ground. Bull Earthq Eng 16(12):5821-5842. https://doi.org/10.1007/s10518-018-0428-3

11. PIANC (International Navigation Association) (2001) Seismic design guidelines for port structures. International Navigation Association, Rotterdam

12. Ramirez-Henao AF, Smith-Pardo JP (2015) Elastic stability of pile-supported wharves and piers. Eng Struct 97:140151. https://doi.org/10.1016/j.engstruct.2015.04.007

13. Schofield AN (1981) Dynamic and earthquake geotechnical centrifuge modelling. In: Proceeding of the first international conference on recent advanced in geotechnical earthquake engineering and soil dynamics, vol 3, pp 1081-1100 
14. Su L, Lu J, Elgamal A, Arulmoli AK (2017) Seismic performance of a pile-supported wharf: Three-dimensional finite element simulation. Soil Dyn Earthq Eng 95:167-179. https://doi.org/10.1016/j.soildyn.2017.01.009

15. Takahashi A, Takemura J (2005) Liquefaction-induced large displacement of pile-supported wharf. Soil Dyn Earthq Eng 25(11):811-825. https://doi.org/10.1016/j.soildyn.2005.04.010

16. Taylor RE (2014) Geotechnical centrifuge technology. CRC Press, London

17. Yoo MT, Han JT, Choi Jl, Kwon SY (2017) Development of predicting method for dynamic pile behavior by using centrifuge tests considering the kinematic load effect. Bull Earthq Eng 15(3):967-989. https://doi.org/10.1007/ s10518-016-9998-0

18. Yun JW, Han JT, Kim SR (2019) Evaluation of virtual fixed points in response spectrum analysis of a pile-supported wharf. Géotech Lett 9(3):238-244. https://doi.org/10.1680/jgele.19.00013

\section{Publisher's Note}

Springer Nature remains neutral with regard to jurisdictional claims in published maps and institutional affiliations.

Submit your manuscript to a SpringerOpen ${ }^{\circ}$ journal and benefit from:

- Convenient online submission

Rigorous peer review

- Open access: articles freely available online

- High visibility within the field

Retaining the copyright to your article

Submit your next manuscript at $\gg$ springeropen.com 